\title{
THE INFORMATIVE VALUE OF COMMUNICATOR DISAGREEMENT IN GREAT APES FOR THE STUDY OF THE EVOLUTION OF HUMAN INTENTIONAL COMMUNICATION
}

\author{
CHRISTINE SIEVERS ${ }^{* 1,2}$, THIBAUD GRUBER ${ }^{3,4}$, and KLAUS ZUBERBÜHLER ${ }^{3}$ \\ *Corresponding Author: christine.sievers@unibas.ch \\ ${ }^{1}$ Department of Philosophy and Media Studies, University of Basel, Basel, Switzerland \\ ${ }^{2}$ Department of Comparative Cognition, University of Neuchâtel, Neuchâtel, Switzerland \\ ${ }^{3}$ Department of Zoology, University of Oxford, Oxford, UK \\ ${ }^{4}$ Swiss Center for Affective Science, University of Geneva, Switzerland
}

Human intentional communication is a complex back- and- forth between communicators, with speakers providing overtly information to hearers and hearers aiming to understand the transmitted information and responding accordingly, in line with the provided information and their own intentions. In regards to how such a complex form of communicative interaction has evolved from simpler forms of communication, nonhuman great ape communication can serve as a model. Intentional communication in nonhuman primates though is often analyzed solely from the perspective of the signaler. Signalers are supposed to stop producing the signal when their goal is fulfilled and they should display persistence or elaboration behavior in case their goal is not fulfilled (Townsend et al., 2016; Leavens et al., 2005). A recipient's reaction to a possible intentional production from the signaler is then largely ignored. In this framework, situations where no information is openly communicated by the signaler or where recipients make decisions independent of the signaler's potential goal and the signal's intended meaning may qualify as instances of intentional communication. Following from that, very simple forms of interaction may be labeled intentional communication, even though these interactions do not have much in common with human intentional communication. The key to providing a more informative comparison is to explicitly focus on recipient's reactions and signaler's responses in the species supposed to serve as a model. Particularly, cases where producer and recipient disagree are informative because both actors 
can provide clues of their disagreement by indicating a diverging goal or displaying dissatisfaction. Such disagreement may amount to a back-andforth between communicators communicating their respective goals, just as it is the case for human communication. Human communicators tend to engage in a back-and-forth in elaborating openly and extensively on their intentions especially in cases in which the communicators disagree on something. If we found such instances in nonhuman primates, it may first be concluded that nonhuman primates can communicate intentionally in a true sense of intentional communication, that is overtly; second, one could subsequently describe the differences between human and nonhuman intentional communication. To address this, we looked at wild chimpanzees as a model species to find instances of communicative disagreement. We video-recorded travel initiations in wild chimpanzees (Pan troglodytes schweinfurthii) in Budongo Forest, Uganda, using focal animal sampling over a six-month study. We were particularly interested in instances where one individual had the goal of leaving with a recipient, but the recipient did not follow and therefore both engaged in a back-andforth interaction. We found 21 occurrences of such conflicts of interest out of 283 travel initiations (7\%) in various contexts including family travel and courtship. To analyze these instances, we studied vocalizations, gestures, the orientation of the body, the moves and gazes of the partners towards the travel direction and each other, and whether they displayed aggression or extensive waiting. Our data show that wild chimpanzees are capable of communicating and negotiating diverging goals during travel to reach a common outcome, though this remains rare. In conclusion, we documented clear instances of disagreement between chimpanzees and their behavior in attempt to win over the other individual, demonstrating how especially vocalizations play an important role, with up to 32 communicative back-and-forths between chimpanzees, suggesting similarities to human conversation, not just with regard to its turn-taking structure but also in regards to its overt nature. Looking at the distribution of behaviors between initiators and potential followers in all contexts, initiators produced more than double the no. of signals and behaviors. Furthermore, negotiations had the longest duration in consortship contexts, with potential followers displaying significantly more communicative behavior than in other group contexts.

\section{Acknowledgements}

This research was funded by the Swiss National Science Foundation. 


\section{References}

Leavens, D. A., Russell, J. L. \& Hopkins W. D. (2005). Intentionality as measured in the persistence and elaboration of communication by chimpanzees (Pan troglodytes), Child Development, 76, 291-306.

Townsend, S. W., Koski, S., Byrne, R., Slocombe, K., Bickel, B., Braga Goncalves, I., Boeckle, M., Burkart, J., Flower, T., Gaunet, F., Glock, H., Gruber, T., Jansen, D., Liebal, K., Linke, A., Miklosi, A., Moore, R., van Schaik, C., Stoll, S., Vail, A., Waller, B., Wild, M., Zuberbühler, K. \& Manser, M. (2016). Exorcising Grice's ghost: an empirical approach to studying intentional communication in animals, Biological Reviews, doi: 10.1111/brv.12289. [Epub ahead of print]. 